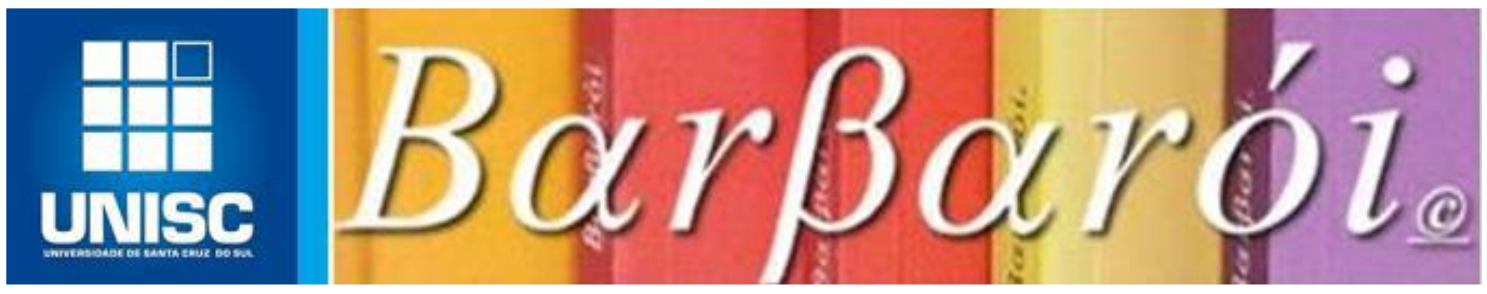

\title{
OBSERVANDO O DESENVOLVIMENTO REGIONAL DO VALE DO RIO PARDO: NOTAS SOBRE AS DINÂMICAS ECONÔMICAS RECENTES
}

\author{
DOI: http://dx.doi.org/10.17058/barbaroi.v0i0.11411

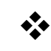

Silvio Cezar Arend

Universidade de Santa Cruz do Sul - UNISC-Brasil

Cidonea Machado Deponti

Universidade de Santa Cruz do Sul - UNISC-Brasil

Rogério Leandro Lima da Silveira

Universidade de Santa Cruz do Sul - UNISC-Brasil

Rosí Cristina Espíndola da Silveira

Universidade de Santa Cruz do Sul - UNISC-Brasil

Grazielle Betina Brandt

Universidade de Santa Cruz do Sul - UNISC-Brasil

Verenice Zanchi

Centro Universitário Dinâmica das Cataratas - UDC

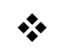

\section{Resumo}

Este artigo aborda as dinâmicas econômicas recentes da região do Vale do Rio Pardo, localizada na área central do Rio Grande do Sul, alisando as relações com o desenvolvimento regional. Nesse sentido, buscou-se analisar as seguintes variáveis para a compreensão do desenvolvimento dessa região em sua dimensão econômica: PIB, VAB, Empregos, Exportações, PIB per capita, Gini, Estrutura Fundiária, Produção Agrícola e IDESE, para melhor compreender o desenvolvimento territorial do Corede VRP. Os resultados apontam que a região ainda permanece vinculada fortemente à produção e transformação de tabaco, embora tenha havido um aumento importante na área e na produção de soja. Também se verifica a manutenção da desigualdade espacial na distribuição da atividade econômica no conjunto do território regional e da sua concentração na área central da região, notadamente no município de Santa Cruz do Sul, polo econômico regional.

Palavras Chave: Desenvolvimento Regional; Corede VRP; Dinâmica econômica. 


\section{Introdução}

O presente artigo apresenta uma análise do processo recente de desenvolvimento regional da região do Conselho Regional de Desenvolvimento - Corede do Vale do Rio Pardo - VRP, localizada na área centro oriental do Rio Grande do Sul, nos últimos 15 anos.

O artigo aborda a dimensão econômica do desenvolvimento regional através da análise de variáveis selecionadas da dinâmica recente da economia regional, com base em um conjunto de dados secundários e indicadores utilizados na elaboração do diagnóstico técnico para o planejamento estratégico do Corede VRP em 2016. Esse diagnóstico técnico contemplou a caracterização da região em seis dimensões: demográfica, ambiental, social, infra estrutural, econômica e a dimensão institucional, das quais a econômica foi selecionada para uma avaliação mais pormenorizada.

Neste olhar da dimensão econômica utilizaram-se as seguintes variáveis: Produto Interno Bruto - PIB, Valor Adicionado Bruto - VAB, Emprego, Exportações, PIB per capita, Índice de Gini, Estrutura Fundiária, Produção Agrícola e Índice de Desenvolvimento Socioeconômico - IDESE. Essas variáveis e indicadores, que aqui se analisam mais detalhadamente, serviram como pano de fundo para analisar economicamente a região.

Com base no referencial teórico utilizado, essa análise pautou-se na utilização dos dados do Perfil Socioeconômico do Corede VRP, elaborado pela Secretaria de Planejamento, Governança e Gestão do Estado do Rio Grande do Sul - SEPLAN-RS e nos dados secundários coletados nos Censos Demográficos de 2000 e 2010 do Instituto Brasileiro de Geografia e Estatística - IBGE; na Fundação de Economia e Estatística - FEE; no Ministério do Desenvolvimento, Indústria e Comércio Exterior - MDIC; no Banco de Dados do OBSERVA-DR; no IBGE; e na Secretaria da Fazenda do Estado do Rio Grande do Sul SEFAZ-RS.

O presente estudo integra ainda as ações de pesquisa do Observatório do Desenvolvimento Regional - OBSERVA-DR, por meio do subprojeto Banco de Dados do Vale do Rio Pardo e procura contribuir para compreender a dinâmica recente de aspectos da economia regional, caracterizando suas permanências e mudanças e suas interrelações com o processo de desenvolvimento regional no território do Vale do Rio Pardo.

$\mathrm{O}$ artigo está dividido em mais três seções, além desta Introdução e das Considerações Finais. Na segunda seção faz-se uma discussão sobre o conceito de desenvolvimento e de desenvolvimento regional e sobre a dimensão econômica desse processo e sua relação e importância com o desenvolvimento territorial. Na terceira seção traz-se uma breve caracterização do território da região do Vale do Rio Pardo e, na quarta seção, são analisadas Barbarói, Santa Cruz do Sul, n.54, p.<234-257>, jul./dez. 2019 
as variáveis e indicadores selecionados que possibilitam observar e compreender as permanências e mudanças na dinâmica recente da economia regional e seus reflexos no desenvolvimento territorial da região.

\section{Desenvolvimento econômico e desenvolvimento regional}

Há vários conceitos/ideias sobre desenvolvimento. No entanto, cabe esclarecer que crescimento e desenvolvimento são termos que não se confundem, embora por muitos anos fossem considerados como sinônimos. Não raras vezes, atualmente, ainda se observa autores vinculados ao mainstream econômico com esta limitada visão de desenvolvimento.

$\mathrm{Na}$ década de 1930, “[...] não se fazia distinção entre desenvolvimento e crescimento econômico porque o primeiro substituía a noção de progresso, sendo que o crescimento econômico era visto como condição necessária e suficiente para a prosperidade e elevação do bem-estar das massas" (Deponti, 2010, p. 38-39) conforme pode ser verificado em Rostow (1974). Para este autor o desenvolvimento ocorre por meio do crescimento por etapas de forma evolucionista, caracterizado pela linearidade, universalidade, positividade. Na América Latina a proposta para o Brasil era imitar o processo de industrialização dos países ricos e avançados, as teorias desenvolvimentistas inspirando-se nas sociedades ocidentais que propunham modelos para o mundo.

Daly (1991, p. 14) também diferencia crescimento de desenvolvimento: "Crescer significa aumentar naturalmente el tamaño (...) Desarrollarse significa expandir o realizar las potencialidades (...) a un estado más pleno, mayor o mejor”. O crescimento está relacionado, portanto, com o incremento quantitativo da escala física, enquanto o desenvolvimento é a melhora qualitativa ou o desabrochar de potencialidades. Por isso, o autor afirma que uma economia pode crescer sem se desenvolver ou se desenvolver sem crescer e, ainda, ambas ou nenhuma delas.

Assim, para elucidar a compreensão sobre desenvolvimento, Veiga (2006) afirma que uma definição possível sobre desenvolvimento reside na convergência das ideias de Ignacy Sachs, Amartya Sen e Celso Furtado, que ensinam que o desenvolvimento implica em uma condição de bem estar humano, garantia de liberdades individuais e respeito ao meio ambiente, que é alcançada à medida que o resultado do crescimento econômico "prioriza a melhoria das condições sociais de vida da população" (VEIGA, 2006, p. 82).

Já para Sen (2001) o desenvolvimento tem de estar relacionado, sobretudo, com a melhoria da vida que se leva e das liberdades que se desfruta. Ainda para o autor, expandir as liberdades que se tem razão para valorizar não só torna a vida mais rica e mais desimpedida, Barbarói, Santa Cruz do Sul, n.54, p.<234-257>, jul./dez. 2019 
mas também permite que os seres sociais sejam mais completos, pondo em prática suas volições, interagindo com o mundo em que vivem e influenciando esse mundo, "ter mais liberdade melhora o potencial das pessoas para cuidar de si mesmas e para influenciar o mundo, questões centrais para o processo de desenvolvimento" (SEN, 2001, p. 33).

A compreensão de desenvolvimento de forma ampla considera uma análise multidimensional, multinível, multiescalar. O desenvolvimento pode se caracterizar por políticas, práticas e processos. Neste sentido, desenvolvimento é um processo complexo, um fluxo de atividades ao longo do tempo. Os processos de desenvolvimento estão constantemente mudando. A natureza do desenvolvimento é a mudança que é modelada, formada e remodelada na prática. Assim, para uma mesma pergunta podem aparecer respostas novas com o tempo. O desenvolvimento é construído passo a passo, esses passos são lentos e frequentemente invisíveis. Os processos de desenvolvimento vão progressivamente se desdobrando com o passar do tempo. O desenvolvimento pode ser compreendido como o uso sustentável dos recursos naturais, a ampliação das liberdades individuais, a eliminação da pobreza e a inclusão social.

A dimensão econômica é importante quando se trabalha qualquer diagnóstico, seja de um país, de um estado ou de um município. Entender como as variáveis econômicas afetam e influenciam uma determinada região é necessário para a compreensão de como funciona a dinâmica da economia da região estudada e como se pode promover seu desenvolvimento. Mas a análise de uma região não pode se esgotar nesta dimensão. Outras dimensões são necessárias para definir um estado de real "desenvolvimento" para a região e sempre serão necessários parâmetros e metas, definidos pelos atores regionais, seja em relação a outras regiões, seja em relação ao próprio processo de construção da região.

A visão corrente até meados dos anos de 1970 tratava crescimento econômico e desenvolvimento como semelhantes. Entretanto, desenvolvimento é algo mais amplo que crescimento econômico, pois pressupõe, além de crescimento da produção e da renda per capita da população, melhoria na qualidade de vida. O desenvolvimento econômico pode ser entendido como um processo pelo qual a renda nacional real de uma economia aumenta durante um longo período de tempo. O desenvolvimento econômico encontra-se no plano do estudo das mudanças descontínuas ou saltos do sistema econômico ao longo do tempo.

Para Becker (2008) o desenvolvimento regional é resultado do envolvimento dos agentes regionais, econômicos, sociais e políticos na construção e na execução de um projeto de desenvolvimento próprio. Ainda segundo o autor, o desenvolvimento é resultado de dois processos antagônicos: um de cunho econômico, que afirma ser a globalização a direção Barbarói, Santa Cruz do Sul, n.54, p.<234-257>, jul./dez. 2019 
corporativa do desenvolvimento e, outro, que se refere à dinâmica do local. Sendo assim, em uma região como é o caso do Corede VRP, na qual predomina a produção e a comercialização concentrada em um produto principal - o tabaco, o desenvolvimento regional dar-se-á através do resultado dos interesses da economia do corporativismo que consiste na produção e na reprodução do capital. Essa dinâmica da reprodução e da produção é alterada quando a sociedade organizada socialmente torna-se participativa política e economicamente.

Nesse sentido, o desenvolvimento pressupõe que haja um mínimo de organização social, para que os diferentes atores possam ser reais protagonistas dos processos de transformação. É o que Remmers (2000) argumenta: que o desenvolvimento endógeno é aquele que entende e fomenta a capacidade 'localizadora' dos atores locais. Na concepção do autor, a localização é um processo social, no qual as pessoas, de modo progressivo, percebem que exercem controle sobre a direção de suas vidas, dentro de um contexto global.

A partir dessa compreensão e do envolvimento da sociedade, se começa a pensar em desenvolvimento regional, que por certo vai além do desenvolvimento econômico, pois pressupõe também a qualidade de vida dos seus indivíduos, mas que também tem neste importante condição e suporte material e de recursos econômicos para o desenvolvimento territorial. Analisar e compreender a região do Corede VRP, portanto, é pertinente para que se possa entender a situação dessa região e se ela pode ou não se configurar como um modelo de desenvolvimento regional.

\section{A região do Corede Vale do Rio Pardo}

O território da região de abrangência do Conselho Regional de Desenvolvimento do Vale do Rio Pardo (Corede/VRP) situa-se na região centro-oriental do Rio Grande do Sul. O território regional é constituído por 23 municípios. Sua extensão territorial abrange uma área de $13.171,7 \mathrm{~km}^{2}$ e atualmente possui uma população de aproximadamente 408.583 habitantes, resultando em uma densidade demográfica média de 31,02 habitantes $/ \mathrm{km}^{2}$ (FEE, 2016).

Os vinte e três municípios que atualmente constituem o Corede do Vale do Rio Pardo são os seguintes: Arroio do Tigre, Boqueirão do Leão, Candelária, Encruzilhada do Sul, Estrela Velha, General Câmara, Herveiras, Ibarama, Lagoa Bonita do Sul, Mato Leitão, Pantano Grande, Passa Sete, Passo do Sobrado, Rio Pardo, Santa Cruz do Sul, Segredo, Sinimbu, Sobradinho, Tunas, Vale do Sol, Vale Verde, Venâncio Aires e Vera Cruz. Na figura 1 é possível observar a configuração territorial da região e a localização dos vinte e três municípios e de suas respectivas sedes municipais. 
A configuração territorial da região revela a existência de dois subespaços com distintas formações territoriais, separados pela linha da encosta da serra, que segue aproximadamente, de leste para oeste, passando pelo limite sul dos municípios de Candelária, Vera Cruz, Santa Cruz do Sul, Venâncio Aires. Ao norte dessa linha, tem-se um desses espaços que é constituído por municípios com média e pequena dimensão, localizados em áreas de relevo mais acidentado, e com o predomínio da pequena propriedade familiar. Já o outro espaço, localiza-se ao sul dessa linha imaginária, é integrado por municípios de grande dimensão territorial localizados em áreas de relevo mais ondulado e com o predomínio das grandes propriedades de criação de gado e/ou produção de lavouras agroindustriais.

O território regional é constituído por municípios de desiguais dimensões espaciais. Compõem esse conjunto regional tanto municípios territorialmente maiores, como os casos de Rio Pardo e Encruzilhada do Sul - criados ainda no século XIX, no contexto da ocupação e colonização das terras da parcela meridional da região, por lusos, açorianos e militares lusobrasileiros -, quanto pequenos municípios, criados mais recentemente, durante o final da década de 1980 e durante a década de 1990, em consequência do intenso processo de emancipações municipais que ocorreu na região.

\section{FIGURA 1 - Localização da região do Corede Vale do Rio Pardo}

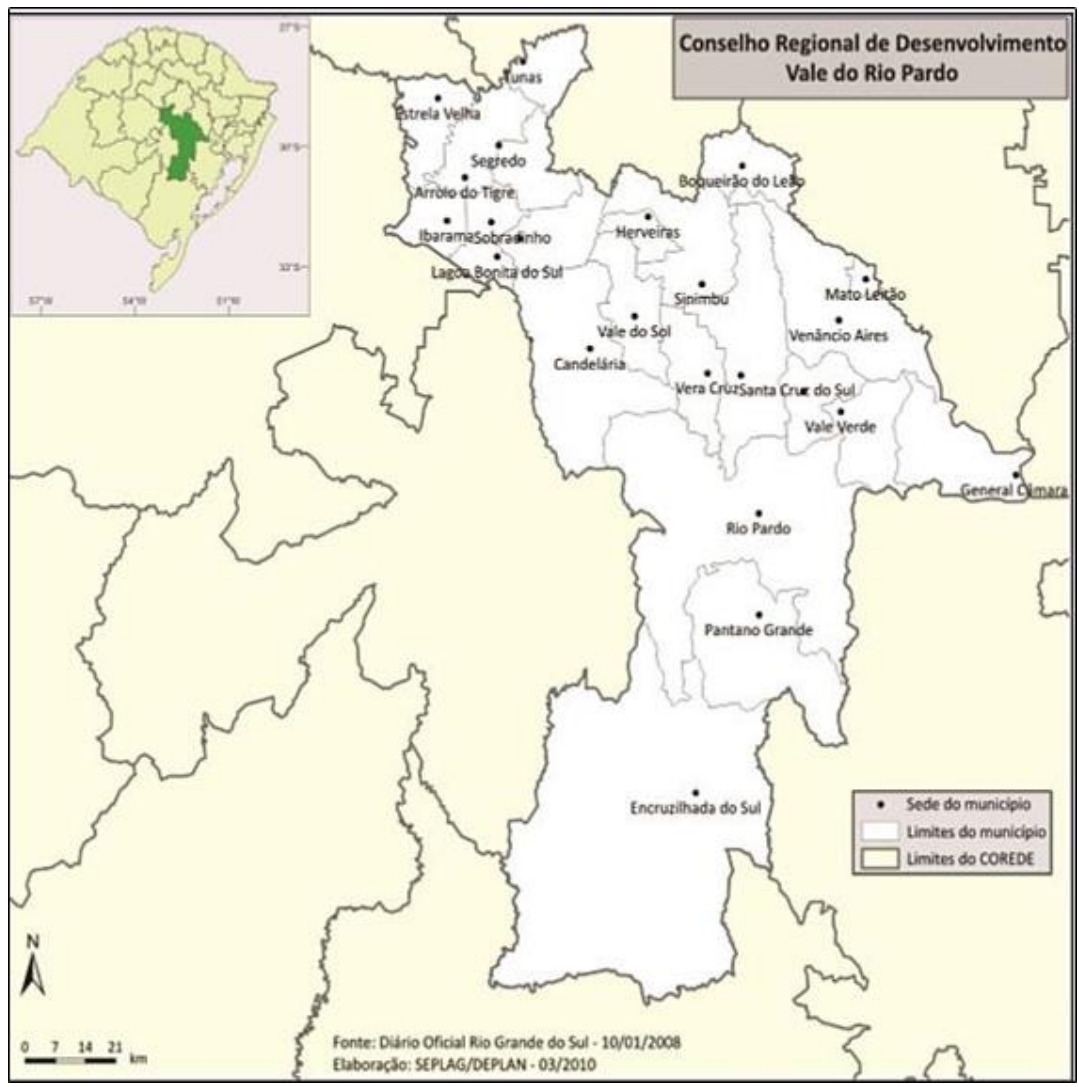

Barbarói, Santa Cruz do Sul, n.54, p.<234-257>,jul./dez. 2019 
Fonte: SEPLAN-RS (2015).

A região do Vale do Rio Pardo é geograficamente heterogênea e apresenta significativas diferenças, particularidades e desigualdades socioespaciais em seu território, relativas ao processo de formação histórica e desenvolvimento econômico e social, permitindo identificar a existência de três microrregiões: Norte, Centro e Sul (Figura 2).

A microrregião Centro caracteriza-se fundamentalmente pela forte presença das empresas multinacionais agroindustriais de fumo em folha, o que influencia diretamente na organização dos espaços urbanos e rurais.

FIGURA 2- A região do Vale do Rio Pardo e suas microrregiões

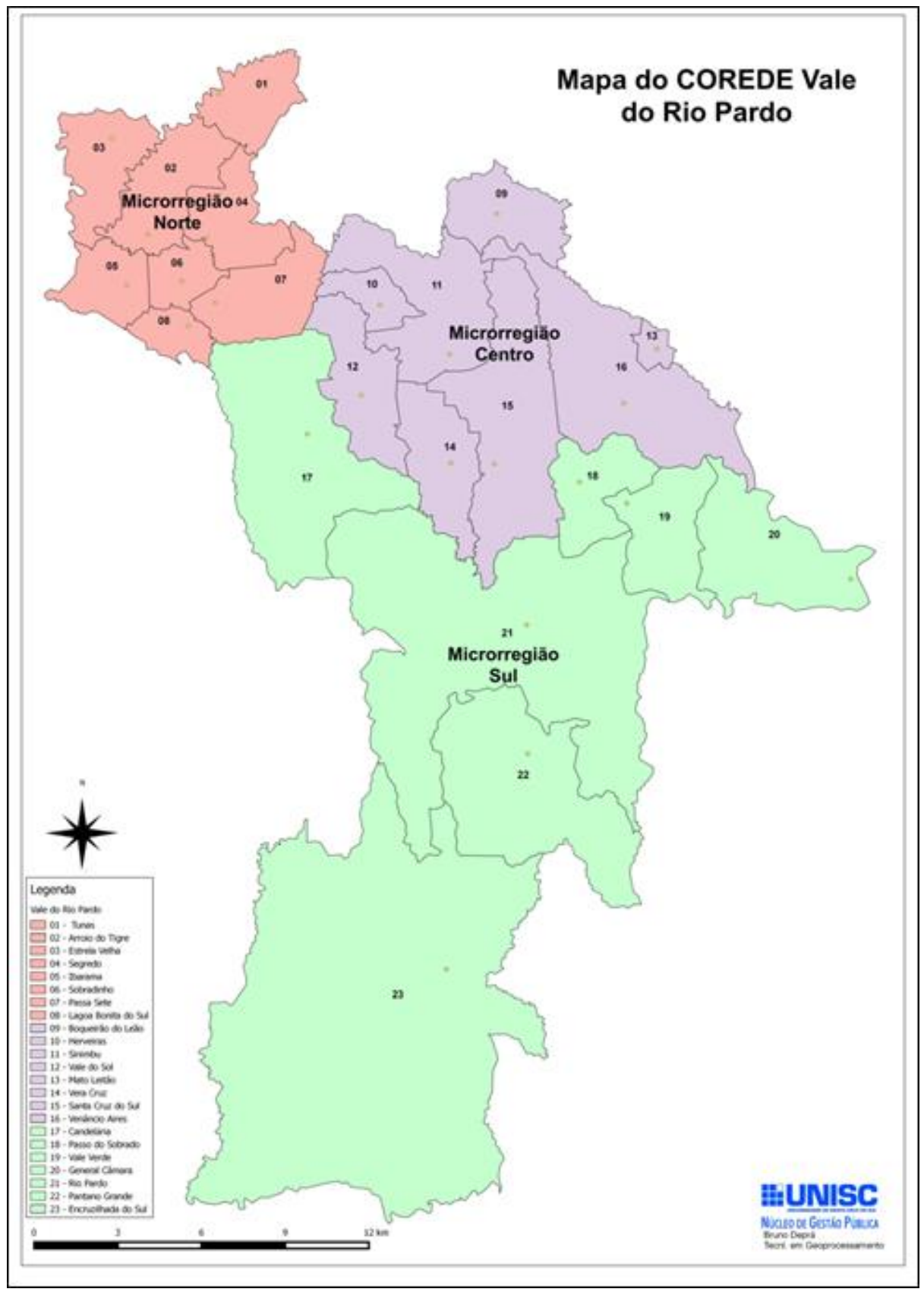

Barbarói, Santa Cruz do Sul, n.54, p.<234-257>, jul./dez. 2019 
Fonte: SILVEIRA e PETRY (2017).

Santa Cruz do Sul concentra em sua área urbana três atividades geradoras da dinâmica regional que lhe concede o papel de cidade polo regional: em primeiro lugar, a presença das principais sedes destas empresas, tais como Souza Cruz, Philip Morris e Universal Leaf Tabacos Ltda.; em segundo lugar, a criação em 1993 da Universidade de Santa Cruz do Sul (UNISC) que se constitui em um forte elemento atrativo de impacto social e econômico na região; e, em terceiro lugar, a constituição de um amplo e diversificado setor de comércio e serviços que atende à demanda regional. As cidades de Venâncio Aires e Vera Cruz se articulam em rede a estas atividades, constituindo-se em espaços de expansão econômica e administrativa destas atividades e também como cidades onde se originam importantes fluxos pendulares para trabalho e estudo. O traço herdado da influência dos descendentes dos imigrantes alemães ainda é forte, podendo ser identificado de forma evidente nas práticas socioespaciais locais, nas construções e na organização dos espaços tanto urbanos como rurais. Tratam-se de municípios também de pequeno porte, com pequenas propriedades rurais familiares.

Já na microrregião Sul observam-se características mais diversas, seja pelo seu processo mais antigo de ocupação do espaço (Rio Pardo constituiu-se num dos primeiros municípios, sendo fundado em 1809), seja pela sua vinculação à dinâmica econômica e sociocultural da metade sul do Estado, através da criação de gado, do cultivo do arroz e da soja, seja pela presença também da produção do fumo em folha. Além da influência dos imigrantes alemães, observa-se uma maior diversidade cultural, vinculada, sobretudo, à cultura luso-brasileira, o que pode ser observado inclusive na formação das cidades - como em Rio Pardo, Encruzilhada do Sul e General Câmara, por exemplo. Os municípios dessa microrregião possuem grande extensão territorial.

Há também que se destacar a desigual distribuição da população no território regional. Em 2010, no conjunto da região, 63,13\% da sua população total residia em áreas urbanas e $36,87 \%$ da população residia em áreas rurais. Quando se observam os dados municipais verifica-se que essa distribuição se diferencia significativamente. Enquanto em Santa Cruz do Sul (microrregião centro) e em Pantano Grande (microrregião sul), tem-se o predomínio da população urbana, com uma taxa de urbanização, de respectivamente, $88,86 \%$ e de $84,02 \%$, em Vale do Sol (microrregião centro) e em Herveiras (microrregião norte), tem-se respectivamente, o predomínio da população rural, com taxas de urbanização de apenas $11,28 \%$ e $13,00 \%$ (IBGE, 2010). 
Em 2010, Santa Cruz do Sul, Venâncio Aires, Rio Pardo, Encruzilhada do Sul, Candelária, Vera Cruz e Sobradinho representam $87,02 \%$ da população urbana da região. O maior crescimento da população urbana, entre 2000 e 2010, foi registrado nos municípios de Estrela Velha $(74,96 \%)$ e Vale do Sol $(73,47 \%)$, enquanto a média de crescimento urbano da região ficou em $11,01 \%$. Observa-se que os maiores vazios demográficos se localizam notadamente nas áreas rurais da porção sul da região do Vale do Rio Pardo, em virtude da sua estrutura fundiária, atividade agropastoril e silvicultura: Encruzilhada do Sul e Pantano Grande, 7,2 hab/km² e 11,6 hab/ $\mathrm{km}^{2}$ respectivamente (IBGE, 2000 e 2010).

\section{A dimensão econômica do desenvolvimento territorial do Vale do Rio Pardo}

Nesta seção são analisadas as variáveis e os indicadores de desenvolvimento, quais sejam: o PIB, o VAB, os dados de emprego, as exportações, o PIB per capita, o coeficiente de Gini, e, ainda, a produção agrícola e o IDESE, no decorrer das últimas décadas. A análise dos mesmos possibilita observar e compreender as permanências e as mudanças na dinâmica recente da economia regional, bem como, seus reflexos no desenvolvimento econômico e regional.

\subsection{Aspectos selecionados do desenvolvimento econômico}

Os dados da produção e estrutura econômica são importantes para o diagnóstico em relação à dimensão econômica. Sendo assim a primeira variável a ser apresentada é o Produto Interno Produto - PIB, que continua sendo um dos principais indicadores de mensuração econômica. Para isso, apresenta-se no Gráfico 1 a composição do PIB dos 23 municípios do Corede VRP. 


\section{GRÁFICO 1 - Participação do PIB dos municípios do VRP sobre o PIB total do Corede}

VRP nos anos de 2000, 2010 e 2013

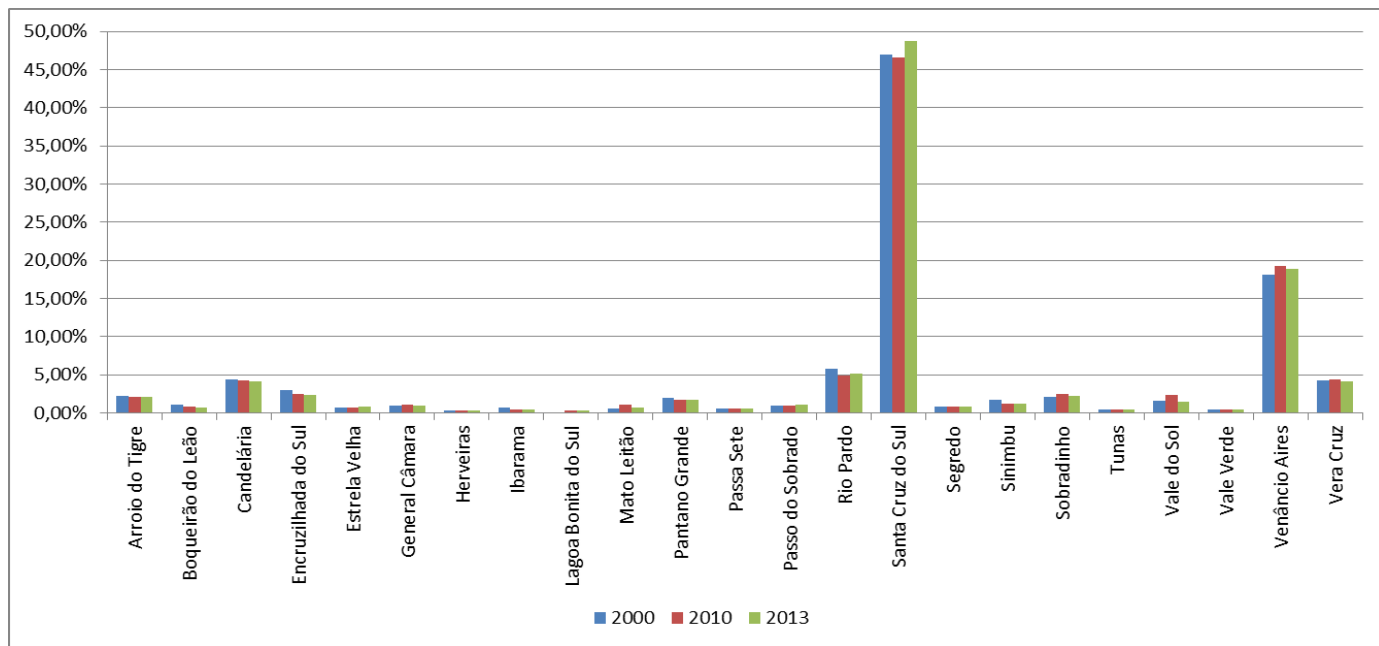

Fonte: Elaborado pelos autores a partir de FEE Dados (2016).

Destaca-se no Gráfico 1 o município de Santa Cruz do Sul com a maior participação percentual do PIB dentre os demais municípios. Em 2013 o PIB de Santa Cruz do Sul foi de $\mathrm{R}$ \$ 6,67 bilhões, correspondendo a 48,8\% do total do Corede Vale do Rio Pardo. Venâncio Aires é o segundo município mais representativo da região, gerando um PIB de R 2,58 bilhões em 2013. Na terceira posição está o município de Rio Pardo, com um PIB R \$ 0,70 bilhão, ou seja, 5,10\% do PIB do Corede VRP. Nesse sentido, os três municípios correspondem a um total de $72,80 \%$ do PIB do Conselho Regional de Desenvolvimento do Vale do Rio Pardo. 
FIGURA 3 - Produto Interno Bruto dos municípios do Corede VRP no ano de 2013

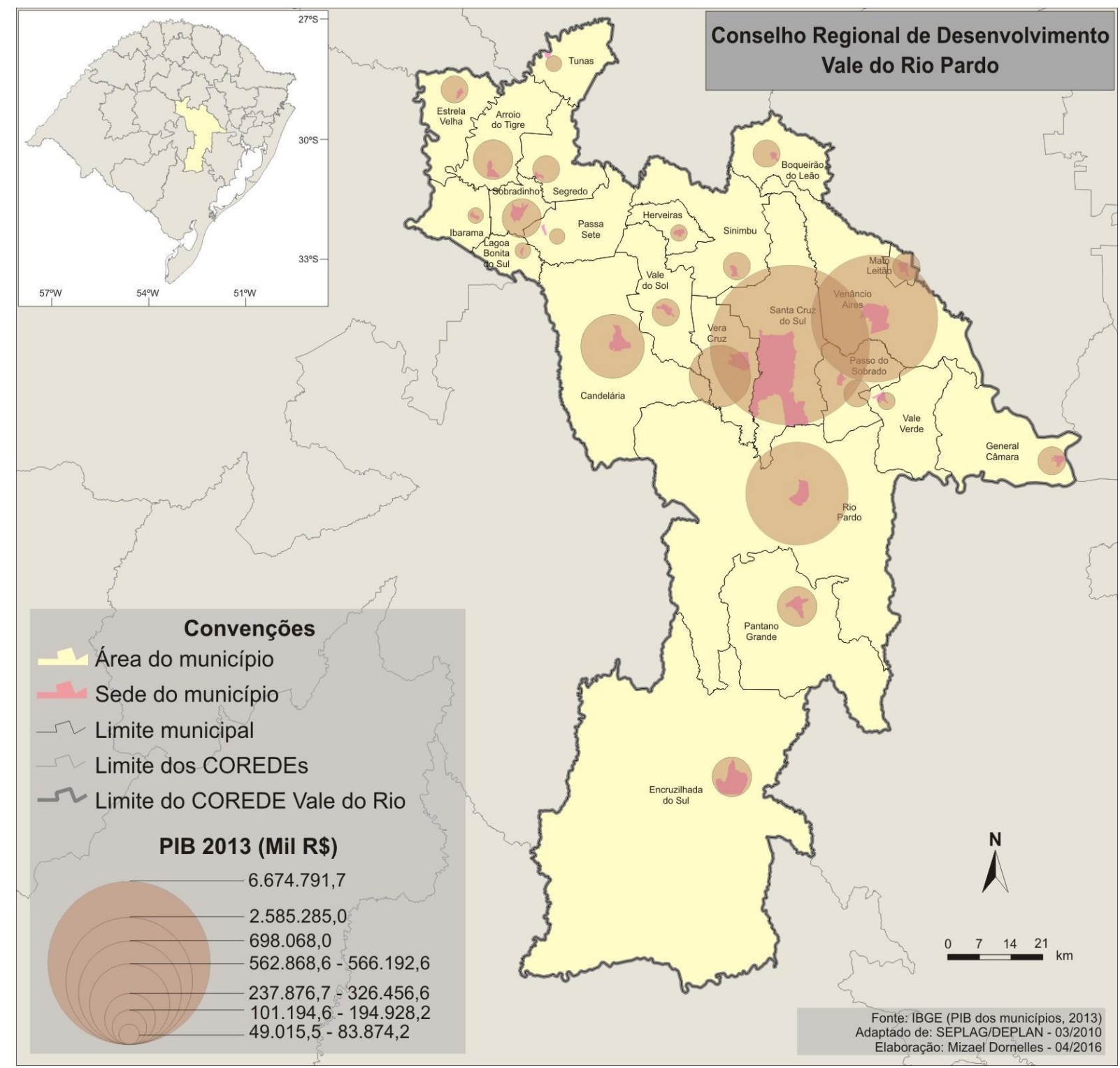

Fonte: Mapa elaborado por Mizael Dornelles a partir das informações do IBGE.

Comparando com o PIB do estado do Rio Grande do Sul, o Corede VRP tinha uma participação de 3,662\% no ano de 2000, passando para 3,715\% em 2010 e 4,131\% em 2013, demonstrando uma evolução positiva no período ao melhorar sua posição relativa aos demais Coredes.

Na Figura 3, acima, é possível visualizar o tamanho relativo do PIB dos municípios e sua concentração, destacando-se os municípios de Santa Cruz do Sul, Venâncio Aires e Rio Pardo, com a maior concentração de PIB como destacado anteriormente.

A partir do olhar do PIB sob o Corede VRP percebe-se que a atividade econômica está concentrada em três municípios, que correspondem à quase três quartas partes de toda a 
produção do Conselho. Além disso, também ocorre uma concentração da produção agrícola, representada pela produção do tabaco.

Outro indicador utilizado para um olhar a partir da dimensão econômica é o Valor Adicionado Bruto - VAB - que é, em uma determinada etapa da produção, a diferença entre o valor bruto produzido nessa etapa (igual às vendas mais acréscimos de estoques) e o consumo intermediário - a etapa anterior (SIMONSEN e CISNE, 1995). Conforme Cosenza (2003), na economia o Valor Adicionado representa toda a riqueza produzida, independente de ter sido vendida ou não.

\section{GRÁFICO 2 - Participação das atividades econômicas na formação do VAB municipal}

\section{no ano de 2013}

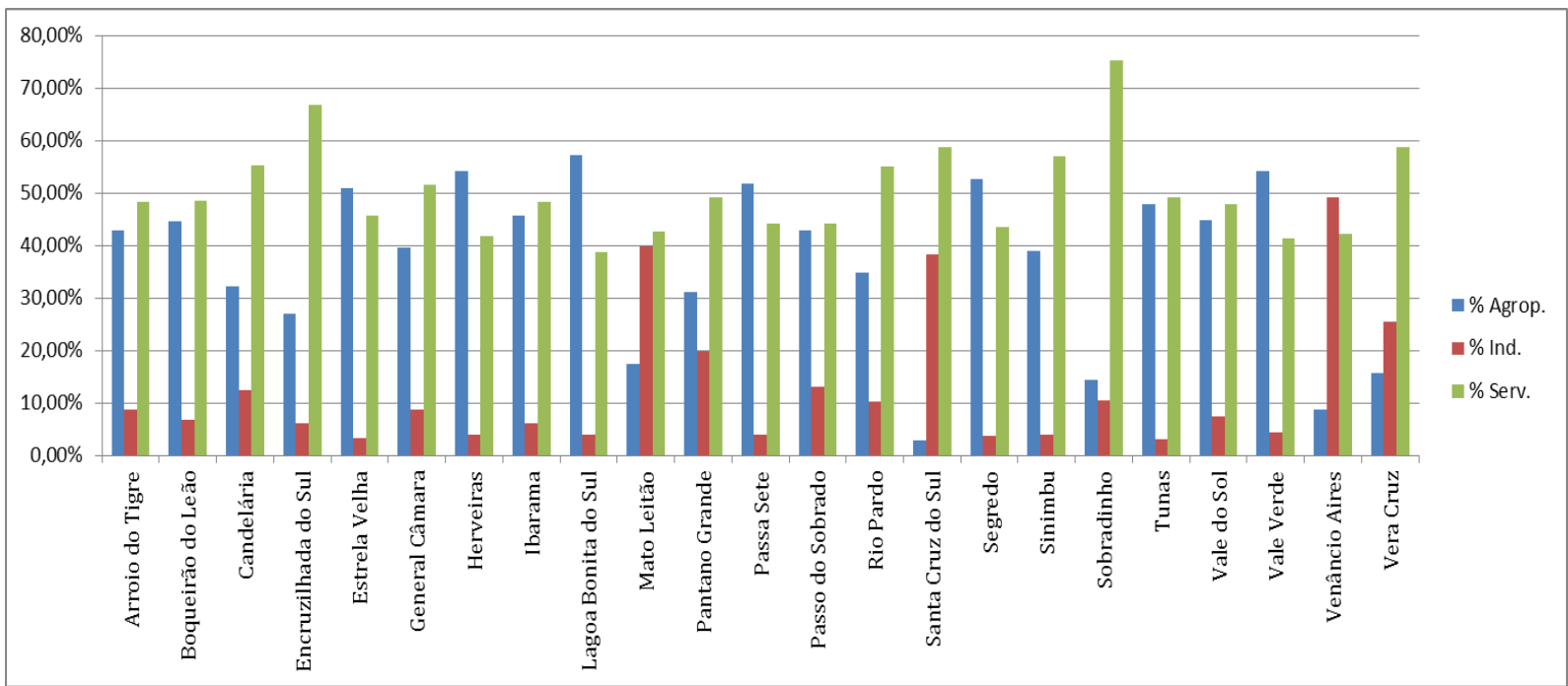

Fonte: Elaborado pelos autores a partir de FEE Dados (2016).

Conforme se apresenta no Gráfico 2, o Valor Adicionado Bruto do Corede VRP em 2013 foi de R\$ 11,6 bilhões. Decompondo essa informação a estrutura do VAB é composta por $15,10 \%$ da agropecuária, $31,05 \%$ da indústria e $53,85 \%$ de serviços, percebendo-se que o VAB do Corede VRP se concentra nos serviços e na indústria.

Desagregando a participação dos setores no VAB dos municípios, Mato Leitão, Venâncio Aires, Santa Cruz do Sul, Vera Cruz e Pantano Grande são os municípios nos quais a atividade industrial apresenta maior expressão, sendo que nos demais municípios este setor de atividade econômica representa menos de $20 \%$ do VAB municipal. Sobradinho, Estrela Velha, Vera Cruz, Santa Cruz do Sul, Sinimbu, Candelária, Rio Pardo e General Câmara são os municípios que se destacam com participação dos serviços superior a 50\% do VAB. Nesse 
sentido, municípios com maior porte é que terão participação mais elevada no VAB de serviços.

Desagregando os dados de emprego por setor, destaca-se com 29,21\% do emprego está na indústria de transformação. A indústria de transformação, segundo a Classificação Nacional de Atividades Econômicas - CNAE , compreende as atividades que envolvem transformação física, química e biológica de materiais, substâncias e componentes para obter produtos novos. Já $27,64 \%$ dos empregos estão no setor de serviços. O setor de serviços é caracterizado por grande heterogeneidade e engloba atividades distintas: segundo a classificação do IBGE (2016), o setor de serviços é subdivido nos subsetores comércio; alojamento (por exemplo, hotelaria) e alimentação (por exemplo, restaurantes); transportes; telecomunicações; intermediação financeira; seguros e previdência privada; atividades imobiliárias; serviços de informática; administração pública; pesquisa e desenvolvimento; educação; saúde e serviços sociais; e serviços pessoais e domésticos. O setor de serviços vem assumindo papel cada vez mais importante no conjunto da economia, do ponto de vista da renda e do emprego gerados.

O setor do comércio apresenta grande variedade de empreendimentos e pode reunir desde grandes multinacionais até pequenos comércios locais. Neste panorama, os pequenos comércios, com até quatro empregados, continuam sendo os responsáveis pela geração de postos de trabalho do setor. Do total de empregos ativos no Corede VRP o setor do comércio concentra $24,56 \%$ dos empregos do Corede VRP. Conforme as informações da RAIS do Ministério do Trabalho, no ano de 2016 29,21\% dos empregos estão concentrados na indústria e o setor de serviços concentra $27,64 \%$ dos empregos.

Em relação às exportações dos municípios do Corede VRP pode-se evidenciar três municípios, que se destacam pela exportação de tabaco: Vera Cruz, no qual $98 \%$ das suas exportações são tabaco; Santa Cruz do Sul cujo total chega a 97\%; e Venâncio Aires com 95\%. Esses dados são preocupantes, pois praticamente todas as exportações desses municípios estão baseadas em um único produto e uma economia atrelada a um único produto fica refém desse produto. No caso dos municípios citados, pode-se observar que suas economias estão atreladas, dependentes de uma única cultura e, nesse sentido, quando o setor vai bem essas economias vão bem, mas quando ocorre qualquer problema as economias desses municípios sofrem conseqüências devastadoras.

O PIB per capita - Produto Interno Bruto dividido pelo número de habitantes - do Corede VRP corresponde a 78,22\% do PIB per capita do Rio Grande do Sul em 2013. Esta relação era de $83,98 \%$ em 2000 , o que indica que, a despeito do crescimento da participação Barbarói, Santa Cruz do Sul, n.54, p.<234-257>, jul./dez. 2019 
do PIB do Corede VRP sobre o PIB estadual de 2000 a 2013 - que indica crescimento mais que proporcional à média do estado - se comparado em termos per capita o crescimento do produto per capita no Vale do Rio Pardo tem ficado aquém daquele verificado no restante do estado, o que indica, em termos da análise tradicional, uma piora nas condições materiais de desenvolvimento da região vis-à-vis o restante do estado.

Cabe neste momento ressaltar que mesmo que ocorra um aumento do PIB per capita isto não significa aumento da renda da população. Pode estar ocorrendo um aumento do PIB enquanto ao mesmo tempo os cidadãos dessa mesma região podem estar ficam mais pobres, pois o PIB per capita representa a média da produção por habitante, não a renda efetivamente recebida. Além disso, da mesma forma não considerada a distribuição desta renda na sociedade. Sendo assim, embora os dados indiquem uma piora relativa da situação da população do Corede vis-à-vis a situação do restante da população gaúcha, somente com esse indicador não é possível fazer considerações sobre a desigualdade de renda e poder aquisitivo e/ou grau de riqueza/pobreza de uma região. O conceito de desenvolvimento regional implica pensar em mudanças na qualidade de vida das pessoas (do que a renda é apenas uma parcela), sobre o que este indicador não faz nenhuma inferência.

Neste sentido, o coeficiente de Gini nos traz maiores informações sobre o comportamento da variável renda na região. O Índice de Gini mede o grau de desigualdade social e o nível de concentração da renda, ou seja, avalia a distribuição da renda domiciliar per capita. O coeficiente varia de 0 a 1 , sendo que o mesmo tende a 0 quando não há desigualdade e a renda de todos os indivíduos têm o mesmo valor e, quando se aproxima de 1, aponta uma desigualdade máxima, ou seja, apenas um indivíduo detém toda a renda (PNUD, 2013).

Ao analisar o Índice de Gini na região concluiu-se que a mesma apresentou diminuição na concentração de renda, de 0,50, em 2000, para 0,46, em 2010. Em outras palavras, houve uma melhora de 0,04 pontos, tendência observada no Estado do Rio Grande do Sul, que reduziu o índice de 0,58 para 0,54. Cabe destacar que o município com maior redução no período foi Estrela Velha, com 0,16 pontos, seguido por Vale Verde, com 0,11 pontos e Herveiras, com 0,10 pontos. Boqueirão do Leão, Passa Sete e Vale do Sol mantiveram os mesmos valores neste intervalo de dez anos. Porém, Ibarama, Lagoa Bonita do Sul, Passo do Sobrado e Tunas totalizaram um aumento na concentração de renda 0,08 pontos (PNUD, 2013). Estes dados indicam que, apesar da renda média da região ser considerada elevada, ela ainda é bastante concentrada. 


\subsection{Mudanças recentes na produção agrícola}

A estrutura fundiária - propriedade da terra em termos de tamanho e distribuição da posse - fornece uma visão panorâmica da área de interesse, fator importante para definir políticas sociais, ambientais e agrícolas. A região do Corede VRP está assim organizada em relação à sua estrutura fundiária: há um total de 38.131 propriedades rurais, que ocupam 997.405 hectares. Do conjunto de propriedades, 47,83\% tem menos de 10 hectares e quase 75\% têm menos de 20 hectares. As grandes propriedades (acima de 500 ha) predominam na proporção sul, nos municípios de Rio Pardo e Encruzilhada. Embora em menor número (apenas 3,7\% das propriedades), estas concentram 28,70\% da área.

É importante destacar que a agricultura familiar representa 90,8\% do número de estabelecimentos e ocupa $44 \%$ da área total. Comparando com o Brasil, verifica-se que no país a agricultura familiar representa $84,4 \%$ dos estabelecimentos rurais, mas tão somente $24 \%$ de área. No Rio Grande do Sul a agricultura familiar participa com 85,7\% dos estabelecimentos e ocupa 30,3\% do total da área.

A principal atividade agrícola desenvolvida nas propriedades rurais do Corede VRP é a produção de tabaco. Esta cultura envolve interesses de vários agentes, como fumicultores, indústria fumageira e o Governo, nas esferas municipal, estadual e federal, em decorrência do volume de impostos arrecadados. A cultura do tabaco representou no ano de 2014 em média $50,41 \%$ do total da produção da lavoura temporária destes municípios. Em relação ao ano de 2010, apresenta uma pequena queda no percentual, em torno de 50\% do total produzido em lavouras temporárias. O município de Pantano Grande é exceção da região, com apenas 5\% da produção total de fumo da lavoura temporária.

Na figura 4 é possível visualizar a distribuição da produção do tabaco na região, destacando-se os municípios de Herveiras e Boqueirão do Leão com as maiores participações do tabaco sobre o total da produção da lavoura temporária. Apesar da concentração na produção do tabaco na região do Corede VRP, outras atividades também podem ser destacadas, como é o caso do cultivo da Erva Mate e da produção do Leite.

\section{FIGURA 4 - Participação do tabaco na lavoura temporária nos municípios do Corede VRP em 2013}




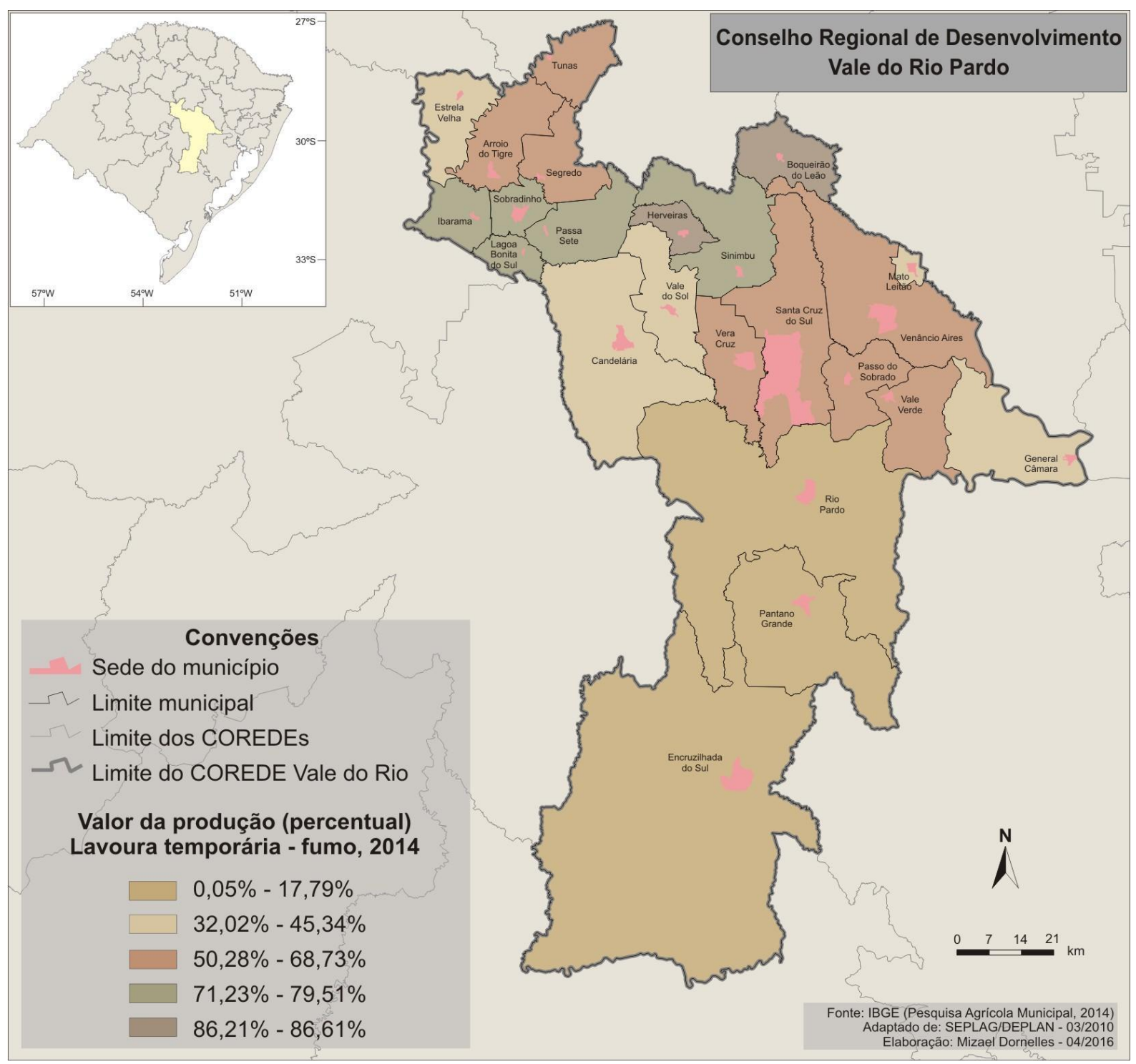

Fonte: elaborado por Mizael Dornelles a partir da Pesquisa Municipal IBGE (2016).

A produção de erva mate é predominante no município de Venâncio Aires, que em 2014 produziu um total de 5.231 toneladas do produto. Mato Leitão também se destaca neste cenário com 2.100 toneladas de erva mate colhidas. Além da produção da erva mate destacase também a produção leiteira no VRP com destaque para o município de Venâncio Aires, que no período de 2000 a 2014 é o município com maior produção, com mais de 11.000 mil litros produzidos no ano de 2014. Cabe ressaltar que no ano de 2010 esse município já produziu mais de 14.000 mil litros de leite.

Já o município de Arroio do Tigre tem uma produção de pouco mais de 8.000 mil litros no ano de 2014, e ainda, se destaca o município de Mato Leitão com quase 8.000 mil litros produzidos em 2014. Estes dois municípios, juntamente com Estrela Velha, são os que tiveram maior crescimento da produção no período de 2000 a 2014, enquanto que a maior 
redução foi verificada em Santa Cruz do Sul, que em 2014 produziu em torno da metade de sua produção do início do período. Destaca-se ainda no Corede VRP a produção de arroz, de milho, de mandioca e de soja.

As produções de arroz, milho, mandioca e soja nos municípios do Corede VRP passaram por grandes transformações no período de 2000 a 2014, com algumas culturas reduzindo sua produção (e eventualmente deixando de ser cultivadas) em alguns municípios, sendo substituídas pela soja, que teve o maior crescimento de produção dentre estes produtos.

A cultura do arroz apresentou um crescimento de 43,12\% no volume produzido de 2014 em relação à produção verificada em 2000. Dos 23 municípios do Corede VRP, 11 reduziram a produção de arroz e, destes, em oito municípios não há mais registro de sua produção. Contrapondo esta involução da cultura na região, o município de General Câmara apresentou um crescimento da produção da ordem de 2.210,56\%, passando de 483 t em 2000 para 11.160 em 2014.

Já a produção de milho apresentou um crescimento de 47,50\% no período de 2000 a 2014, também apresentando comportamento diferenciado entre os municípios. Um conjunto de oito municípios apresentou redução da produção, enquanto que sete municípios mais que dobraram a produção de milho no período. Os destaques de maior crescimento da produção são Pantano Grande (402, 77\%), Rio Pardo (288,89\%) e General Câmara, com 284,61\% de crescimento da produção.

Outra cultura que cabe destacar é a produção de mandioca, que dentre este conjunto de principais culturas avaliadas, teve um crescimento da produção de apenas 11,91\% no período de 2000 a 2014. Doze municípios reduziram a produção no período e o destaque é a elevação da produção em Estrela Velha, da ordem de 233,33\%. Os maiores produtores de mandioca no Vale do Rio Pardo são os municípios de Rio Pardo e Venâncio Aires, que produzem mais que o dobro do terceiro colocado, Santa Cruz do Sul.

A última cultura da lavoura temporária destacada para análise da evolução no período de 2000 a 2014 é a soja, que apresentou um crescimento de produção da ordem de 511,03\% no conjunto dos 23 municípios do Corede VRP. Os destaques de maior aumento da produção são os municípios de Vale Verde $(8.113,33 \%$ de aumento da produção), General Câmara (7.628,81\%), Venâncio Aires (7.307,41\%), Encruzilhada do Sul $(5.960,61 \%)$ e Mato Leitão (2.690,70\% de aumento da produção). Apenas no município de Herveiras não há registro da produção de soja.

Esse conjunto de informações principalmente no que tange à produção agrícola da região do Corede VRP, mostra que apesar da renda dessa região ter na produção do tabaco sua Barbarói, Santa Cruz do Sul, n.54, p.<234-257>, jul./dez. 2019 
concentração, existem outras culturas, embora ainda com menor expressão no valor bruto da produção agrícola, mas com expansão da área e que, gradativamente, mudam o perfil de produção da região.

\subsection{Incorporando outras dimensões do desenvolvimento: o IDESE}

O Índice de Desenvolvimento Socioeconômico - IDESE é um indicador importante para avaliar a situação das dimensões em relação ao padrão ideal/almejado de desenvolvimento, mostrando a posição relativa dos municípios e qual a distância do ideal a ser alcançado, portanto fundamental para a definição de políticas públicas.

O IDESE do Rio Grande do Sul no ano de 2013 foi de 0,747. Desagregando esse resultado em seus indicadores parciais, o índice da Educação, para o Rio Grande do Sul, é de 0,679; já o indicador de Renda é de 0,752; e o indicador de Saúde é de 0,809. A análise desses dados desagregados é importante para verificar as disparidades entre os indicadores parciais, pois, sendo uma média, algum indicador parcial terá melhor desempenho que o indicador geral e, consequentemente, ao menos um terá desempenho inferior à média, sendo prioritário de ação.

Um exemplo disso pode ser verificado no município de Santa Cruz do Sul, que está em primeiro lugar quando se olha o indicador de forma agregada, ou seja, sob a ótica conjunta da Educação, da Renda e da Saúde. Ao olhar cada item que compõe o IDESE de forma separada para o município de Santa Cruz do Sul, o mesmo está em segundo lugar no Corede VRP em relação à Educação, em primeiro lugar em relação à Renda e somente em quinto lugar em relação à Saúde.

Já o segundo lugar no indicador do IDESE geral de 2013 do Corede VRP é do município de Mato Leitão. Ao olhar o indicador de Educação, o mesmo município aparece em primeiro lugar, em relação à Renda fica com a sexta posição e em relação à Saúde novamente com o primeiro lugar. O município que ocupa a terceira posição em relação ao IDESE de 2013 do Corede VRP é Venâncio Aires. Desagregando o indicador, o município de Venâncio Aires em relação à Educação está na décima primeira posição, em relação à Renda ocupa a segunda posição e em relação à Saúde ocupa a quarta posição.

Por fim o município que está na quarta posição em relação ao IDESE de 2013 do Corede VRP é Estrela Velha. Ao analisar cada indicador separadamente, pode-se observar que em relação à Educação o município de Estrela Velha está na sexta posição, em relação à Renda na terceira posição e, na Saúde, ocupa a oitava posição. A análise desse indicador é 
importante, principalmente, olhar para sua composição, pois, com isso é possível ver de fato como os municípios estão frente à Educação, à Renda e à Saúde.

Sem essa análise desagregada pode-se cometer o erro de dizer, por exemplo, que o Corede VRP está bem em relação ao IDESE, se comparado com o Rio Grande do Sul, mas é preciso de fato confirmar isso frente aos indicadores parciais que o compõem e também olhar esses indicadores município a município.

\section{GRÁFICO 3 - Evolução do IDESE dos municípios do Corede VRP para os anos de 2010} a 2013

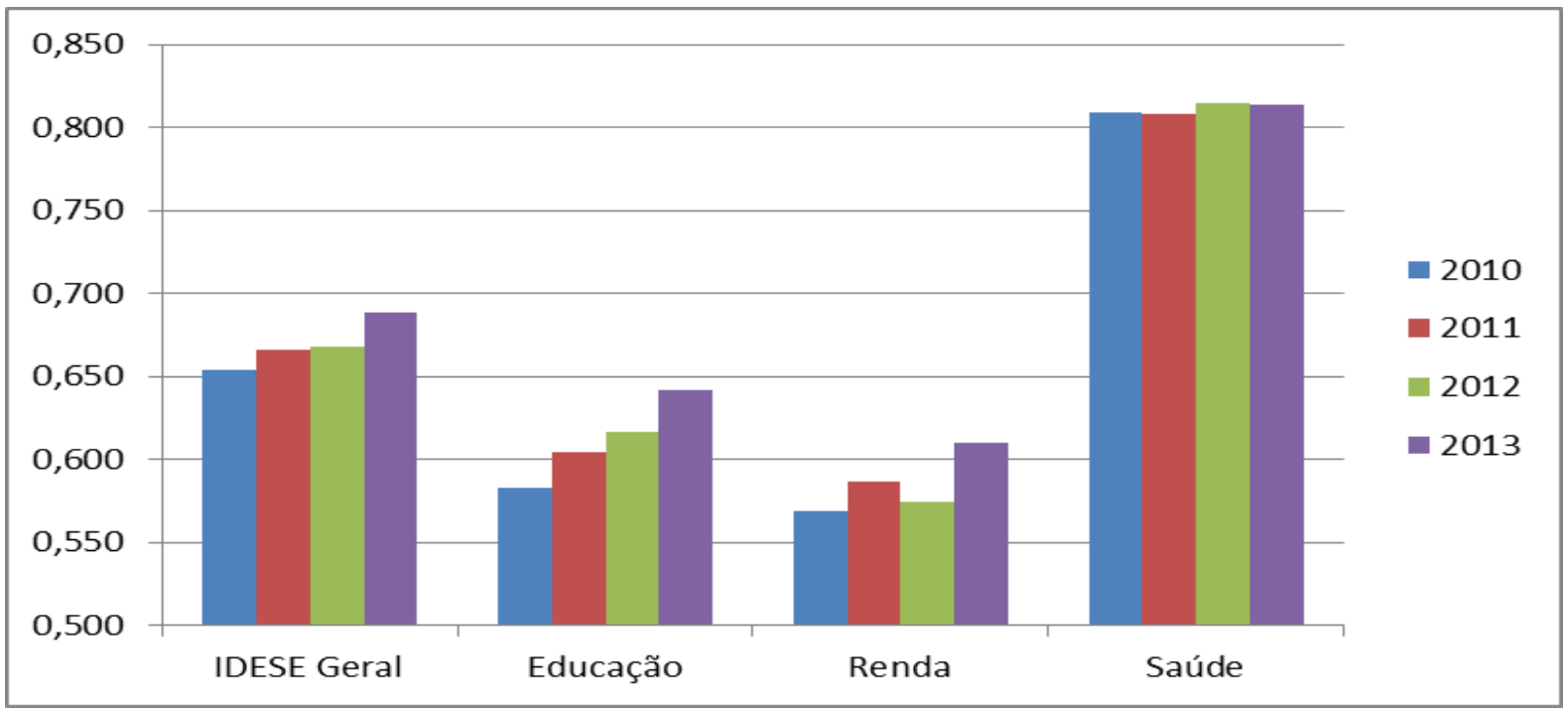

Fonte: Elaborado pelos autores a partir de FEE Dados (2016).

Nesse sentido o Gráfico 3 apresenta o IDESE dos municípios do Corede VRP de forma geral e também separado por Educação, Renda e Saúde, acompanhando o índice de 2010 a 2013. Em geral o Corede VRP está melhorando seu desempenho ao passar dos anos, porém, cabe ressaltar que mesmo com um índice crescente ao longo do tempo alguns municípios que compõem o Corede VRP têm indicadores muito abaixo do índice agregado do Conselho.

\section{Considerações finais}

O conjunto de informações e dados levantados proporciona uma série de observações sobre o desenvolvimento econômico da região, principalmente quanto à heterogeneidade entre os 23 municípios que o compõem. Essa heterogeneidade que caracteriza o Corede VRP exige um planejamento que considere essa diversidade, transformando-a em resultados positivos para os municípios. 
Cabe salientar que a heterogeneidade entre os municípios também aparece quando se observa a distribuição das propriedades rurais, pois dois municípios com grande extensão territorial, Rio Pardo e Encruzilhada do Sul, concentram as maiores propriedades, enquanto outros caracterizam-se por propriedades muito pequenas.

Outra questão relevante é a grande dependência que o Corede VRP tem em relação à cultura do tabaco. Além dos riscos de dependência econômica da região em relação a um único produto, tem-se ainda, a Convenção Quadro para o Controle do Tabaco, que estabelece uma série de medidas que apresentam um quadro de incertezas quanto à continuidade da produção de tabaco na região.

A discussão em torno da produção do tabaco não é nova, mas reincide toda vez que é feito um diagnóstico, principalmente nesta região que tem uma dependência expressiva em relação ao mesmo. Nesse sentido, é importante estabelecer mecanismos e estratégias para que seja possível enfrentar as dificuldades sociais e econômicas que poderão ser geradas a médio e a longo prazo em relação a um tratado internacional como a Convenção Quadro para o Controle do Tabaco.

Com relação à produção agrícola da região do Corede VRP, cabe destacar que apesar do tabaco ser a base da renda dessa região, outros cultivos, ainda que incipientes em termos de representatividade no valor bruto da produção agrícola, estão em plena expansão de suas áreas, o que gradualmente deve mudar o perfil de produção da região. Dentre estes a produção de soja merece acompanhamento e estudos futuros.

Ao analisar o PIB do Corede do Vale do Rio Pardo, destaca-se que três municípios Santa Cruz do Sul, Venâncio Aires e Rio Pardo - concentram um total de 72,80\% desse indicador. Apesar da melhora do Índice de Gini na região - diminuição na concentração de renda -, de 0,50, em 2000, para 0,46, em 2010, ou seja, de 0,04 pontos, a mesma observada no Estado do Rio Grande do Sul e da renda média da região ser considerada elevada, ela ainda é bastante concentrada, tanto em termos pessoais (Gini), quanto espacial (PIB).

Por fim, apesar dessas mudanças no perfil da produção agrícola e avanços em alguns indicadores, ainda se mantém a desigualdade espacial na distribuição da atividade econômica no conjunto do território regional e da sua concentração na área central da região, notadamente no município de Santa Cruz do Sul, polo econômico regional.

\section{OBSERVING THE REGIONAL DEVELOPMENT OF THE PARDO RIVER VALLEY: NOTES ON RECENT ECONOMIC DYNAMICS}

\section{Abstract}


This article discusses the recent economic dynamics of the Vale do Rio Pardo region, located in the central area of Rio Grande do Sul, smoothing relations with regional development. In this sense, we aimed to analyze the following variables to understand the development of this region in its economic dimension: GDP, GVA, Employment, Exports, GDP per capita, Gini, Land Structure, Agricultural Production and IDESE, to better understand territorial development of Corede VRP. The results indicate that the region still remains strongly linked to the production and processing of tobacco, although there has been a significant increase in the area and in the production of soybeans. It is also verified the maintenance of spatial inequality in the distribution of economic activity in the region as a whole and its concentration in the central area of the region, especially in the municipality of Santa Cruz do Sul, regional economic hub.

Key Words: Regional Development; Corede VRP; Economic dynamics.

\section{OBSERVANDO EL DESARROLLO REGIONAL DEL VALE DO RIO PARDO: NOTAS SOBRE LAS DINÁMICAS ECONÓMICAS RECIENTES}

\section{Resumen}

Este artículo aborda las dinámicas económicas recientes de la región del Vale do Rio Pardo, ubicada en el área central de Rio Grande do Sul, alisando las relaciones con el desarrollo regional. En este sentido, se buscó analizar las siguientes variables para la comprensión del desarrollo de esa región en su dimensión económica: PIB, VAB, Empleos, Exportaciones, PIB per cápita, Índice de Gini, Estructura Fundiaria, Producción Agrícola e IDESE, para comprender mejor el desarrollo territorial del Corede VRP. Los resultados apuntan que la región sigue siendo vinculada fuertemente a la producción y transformación de tabaco, aunque ha habido un importante aumento en el área y en la producción de soja. También se verifica el mantenimiento de la desigualdad espacial en la distribución de la actividad económica en el conjunto del territorio regional y de su concentración en el área central de la región, notadamente en el municipio de Santa Cruz do Sul, polo económico regional.

Palabras Clave: Desarrollo Regional; Corede VRP; Dinámica económica.

\section{Referências}

BECKER, D. F. A economia política do (des.) envolvimento regional contemporâneo. IN: BECKER, D. F. e WITTMANN, M. L. (org.). Desenvolvimento Regional: abordagens interdisciplinares. 2. ed. Santa Cruz do Sul: EDUNISC, 2008, p. 37-66.

CENSOS Demográficos: Banco de dados da FEE. Disponível em: <http://www.fee.rs.gov.br /indicadores/populacao/censos-demograficos/>. Acesso em: 11 mar. 2016.

CIDADES - Síntese das informações: Banco de dados agregados do IBGE. Disponível em: $<\mathrm{http}$ //Www.cidades.ibge.gov.br/comparamun/compara.php?lang=\&coduf=43\&idtema=16\&c $\mathrm{odv}=\mathrm{v} 06 \&$ search=rio-grande-do-sul|arroio-do-tigre|sintese-das-informacoes- $>$. Acesso em: 5 abr. 2016.

COSENZA, J. P. A Eficácia Informativa da Demonstração do Valor Adicionado. Revista Contabilidade e Finanças. USP, São Paulo, Edição Comemorativa, p. 7-29, out. 2003.

DALY, H. E. A economia ecológica e o desenvolvimento sustentável. Rio de Janeiro: ASPTA, 1991. 
DEPONTI, C.M. Indicadores para avaliação da sustentabilidade em contextos de desenvolvimento rural local. Monografia de Especialização. UFRGS: Porto Alegre, 2010. IBGE. Censo Demográfico 2010: Banco de dados agregados do IBGE. Rio de Janeiro: IBGE. Disponível em: <http://www.sidra.ibge.gov.br/bda/tabela/ listabl.asp? $\mathrm{z}=\mathrm{t} \& \mathrm{o}=25 \& \mathrm{i}=\mathrm{P} \& \mathrm{c}=1378>$. Acesso em: 24 mar. 2016.

IBGE. Censo Demográfico 2000: Banco de dados agregados do IBGE. Rio de Janeiro: IBGE. Disponível em: <http://www.sidra.ibge.gov.br/bda/tabela/ listabl.asp? $\mathrm{z}=\mathrm{t} \& \mathrm{o}=25 \& \mathrm{i}=\mathrm{P} \& \mathrm{c}=1378>$. Acesso em: 24 mar. 2016.

IDESE - Série Histórica: Banco de dados da FEE. Disponível em: <http://www.fee.rs.gov.br/ indicadores/indice-de-desenvolvimento-socioeconomico/>. Acesso em: 8 mar. 2016.

OBSERVA/DR. Banco de dados Vale do Rio Pardo. Disponível em: <http://observadr.org.br/ portal/banco-de-dados-regionais/vale-do-rio-pardo>. Acesso em: 23 mar. 2016.

PIB Municipal - Série Histórica: Banco de dados da FEE. Disponível em: <http://www.fee.rs.gov.br/indicadores/pib-rs/municipal/serie-historica/>. Acesso em: 10 mar. 2016.

PNUD - Programa das Nações Unidas para o Desenvolvimento. Disponível em: <http://www.atlasbrasil.org.br/2013/> Acesso em: 24 mar. 2016.

PRODUÇÃO Agrícola Municipal: Banco de dados agregados do IBGE. Disponível em: $<$ http://www.sidra.ibge.gov.br/bda/acervo/acervo9.asp?e $=c \& p=P A \& z=t \& o=11>$. Acesso em: 24 mar. 2016.

PRODUÇÃO Pecuária Municipal: Banco de dados agregados do IBGE. Disponível $\mathrm{em}:\langle\mathrm{http} / / / \mathrm{www}$. sidra.ibge.gov.br/bda/acervo/acervo9.asp? $=\mathrm{c} \& \mathrm{p}=\mathrm{PP} \& \mathrm{z}=\mathrm{t} \& \mathrm{o}=11>$. Acesso em: 22 mar. 2016.

RAIS - MINISTÉRIO DO TRABALHO. Disponível em: <http://www.rais.gov.br/sitio/ consulta_trabalhador_identificacao.jsf>. Acesso em: 20 abr. 2016.

REMMERS, G. El Desarrollo Endógeno en Zonas Rurales: acertando en un blanco móvil. In: Guzmán Casado, G; Gonzáles de Molina, M.;Sevilla Guzmán, E. (eds). Introducción a la Agroecología como Desarrollo Rural Sostenible. Madrid: Mundiprensa, 2000, p.534.

RIO GRANDE DO SUL. Secretaria do Planejamento, Mobilidade e Desenvolvimento Regional - SEPLAN-RS. Perfil Socioeconômico do COREDE Vale do Rio Pardo. Porto Alegre: DPG, 2015.

ROSTOW, W. W. As cinco etapas do desenvolvimento - um sumário. In: Etapas do desenvolvimento econômico (um manifesto não-comunista). Rio de Janeiro, Zahar editores, 1974.

IPM - Índice de participação dos municípios: Banco de dados da SEFAZ-RS. Disponível em: $<$ https://www.sefaz.rs.gov.br/Site/MontaMenu.aspx?MenuAlias=m_dwn_apuracao_ipm_arq_ ipm>. Acesso em: 8 mar. 2016. 
SEN, Amartya. Desenvolvimento como liberdade. São Paulo: Companhia das Letras, 2000.

SILVEIRA, Rogério Leandro Lima da; e PETRY, Heitor. (ORG). PLANO ESTRATÉGICO DE DESENVOLVIMENTO REGIONAL DO VALE DO RIO PARDO (2015-2030). 01. ed. Santa Cruz do Sul - Rio Grande: Edunisc, 2017. v. 1. 410p.

SIMONSEN, M. H.; CYSNE, R. P. Macroeconomia. 2 ed. São Paulo: Atlas, 1995.

VEIGA, J. E. Desenvolvimento Sustentável: desafio do século XXI. Rio de Janeiro: Editora Garamond Universitária, 2006.

Data de recebimento: $30 / 11 / 2017$

Data de aceite: 13/11/2019

\section{Sobre os autores:}

Silvio Cezar Arend é Economista (FISC, 1999), Mestre em Economia Rural (UFRGS, 1993) e Doutor em Economia (UFRGS, 2001). Professor da Universidade de Santa Cruz do Sul (UNISC) desde 1990, lotado no Departamento de Ciências Econômicas. Professor no Programa de Pós-graduação em Desenvolvimento Regional (PPGDR), no qual orienta dissertações e teses. Docente dos cursos de Ciências Econômicas e Relações Internacionais, da UNISC. Endereço Eletrônico: silvio@unisc.br

Cidonea Machado Deponti possui Graduação em Ciências Econômicas pela Universidade Federal de Santa Maria-UFSM (1999), Mestrado em Integração Latino-Americana, 2001, pelo Programa de Pós-Graduação em Integração Latino-Americana da UFSM; Especialização em Desenvolvimento Rural e Agroecologia pelo Programa de Pós-Graduação em Desenvolvimento Rural da UFRGS; Doutorado em Desenvolvimento Rural pelo Programa de Pós-Graduação em Desenvolvimento Rural da UFRGS, 2010. Bolsista de Pós-Doutorado Júnior- PDJ (CNPq/UFRGS) no período de abril de 2011 a março de 2012. Atualmente é Docente e Coordenadora Adjunta do Programa de Pós-Graduação em Desenvolvimento Regional da Universidade de Santa Cruz do Sul-RS. Endereço Eletrônico: cidonea@unisc.br

Rogério Leandro Lima da Silveira é Geógrafo. Mestre e Doutor em Geografia Humana pela Universidade Federal de Santa Catarina. Pesquisador do CNPq - 2. Professor titular e pesquisador do Departamento de História e Geografia, e pesquisador e orientador no Programa de Pós-Graduação em Desenvolvimento Regional - Mestrado e Doutorado, da Universidade de Santa Cruz do Sul. É lider do GEPEUR - Grupo de Pesquisa e Estudos Urbanos Regionais (CNPq). Pesquisador Visitante do Centro Interdisciplinar de Ciências Sociais da Universidade Nova de Lisboa - CICS.NOVA Coordenador do Observatório do Desenvolvimento Regional. Endereço Eletrônico: rlls@unisc.br

Rosí Cristina Espíndola da Silveira possui graduação em Engenharia Civil pela Pontifícia Universidade Católica do Rio Grande do Sul - PUC-RS (1988), Especialização em Engenharia para o Saneamento Ambiental pela PUC-RS (1991), Mestrado em Desenvolvimento Regional, na área Técno-Ambiental pela Universidade de Santa Cruz do Sul - UNISC (2000) e Doutorado em Engenharia Ambiental pela Universidade Federal de Santa Catarina - UFSC (2008). Professora adjunta, do Departamento de Engenharia, Arquitetura e Ciências Agrárias (2010-2018); professora do Programa de Pós-Graduação em 
Desenvolvimento Regional - PPGDR (2015-2018). Endereço Eletrônico: rsosices@gmail.com

Grazielle Betina Brandt possui graduação em Relações Públicas (2000) e mestrado em Desenvolvimento Regional pela Universidade de Santa Cruz do Sul (2004). É doutora em Desenvolvimento Regional pela Universidade du Québec (2010). Pós-Doutora no Programa de Pós-Graduação em Planejamento Urbano e Regional da Universidade Federal do Rio Grande do Sul - UFRGS (2018). Bolsista Fulbright no Multinational Institut of American Studies na New York University (2018). Professora visitante da New York University, NYU/Steinhardt, no Programa de Educação, Cultura e Desenvolvimento (2018-2019). Docente e pesquisadora do Departamento de Negócios e Comunicação e do Programa de PósGraduação em Desenvolvimento Regional da UNISC. Endereço Eletrônico: grazielle@unisc.br

Verenice Zanchi possui Graduação em Administração com Habilitação em Comércio Exterior (2002), Especialização em Gestão Empresarial (2004) e mestrado em Desenvolvimento Regional pela Universidade de Santa Cruz do Sul (2013). É doutora em Desenvolvimento Regional pela Universidade de Santa Cruz do Sul (2019). Docente e pesquisadora do Departamento de Administração e do Departamento de Ciências Contábeis da UDC. Endereço Eletrônico: verenice.zanchi@gmail.com 